\title{
NeuroImage
}

\section{Affective response to one's own moral violations}

\author{
S. Berthoz, ${ }^{\text {a,* }}$ J. Grèzes, ${ }^{\mathrm{b}}$ J.L. Armony, ${ }^{\mathrm{c}}$ R.E. Passingham, ${ }^{\mathrm{d}, \mathrm{e}}$ and R.J. Dolan ${ }^{\mathrm{e}}$ \\ ${ }^{a}$ Department of Psychiatry, IMM, University Paris V, France \\ ${ }^{\mathrm{b}}$ LPPA-CNRS-Collège de France, Paris, France \\ ${ }^{\mathrm{c} D o u g l a s}$ Hospital Research Centre, McGill University, Montréal, Canada \\ ${ }^{\mathrm{d}}$ Department of Experimental Psychology, University of Oxford, Oxford, UK \\ ${ }^{\mathrm{e}}$ Wellcome Department of Imaging Neuroscience, ION, UCL, London, UK
}

Received 14 June 2005; revised 16 December 2005; accepted 23 December 2005

Available online 20 February 2006

\begin{abstract}
Morality depends on a set of cultural rules that regulate interpersonal behaviour and provide a basis for social cohesion. The interpretation of moral transgressions and their affective consequences depends on whether the action is intentional or accidental, and whether one is the agent of or witness to the action. We used event-related functional magnetic resonance imaging (fMRI) to investigate whether the amygdala is involved in judging one's own moral violation of social norms. In this study, participants $(n=12)$ were asked to make evaluations regarding the degree of inappropriateness of social behaviours described in stories in which they themselves, or someone else, transgressed social norms either intentionally or accidentally. Consistent with our hypothesis, the amygdala was activated when participants considered stories narrating their own intentional transgression of social norms. This result suggests the amygdala is important for affective responsiveness to moral transgressions.

(c) 2006 Elsevier Inc. All rights reserved.
\end{abstract}

Keywords: Morality; Amygdala; Self; Agency; Intentionality; fMRI

\section{Introduction}

Morality depends on a set of rules designed to regulate interpersonal behaviour and to allow people to live together in harmony (Hogan, 1973). It requires the internalization of the social norms and rules that promote group cohesion and avoid rejection by peers (Hawley, 2003). For long, most of the existing philosophical discussion on moral experience had assumed that moral judgment is rationally based rather than based on affect. Increasing evidence in this field of research indicates however that moral judgment involves intuitive, effortless and emotion-

\footnotetext{
* Corresponding author. Service de Psychiatrie, Institut Mutualiste Montsouris, 75674 Paris, Cedex 14, France. Fax: +33 156616924.

E-mail addresses: sylvie.berthoz@imm.fr, sylvie.berthoz@tiscali.fr (S. Berthoz).

Available online on ScienceDirect (www.sciencedirect.com).
}

based mechanisms (Greene, 2003). On the basis of converging findings in psychology and cognitive neuroscience, a recent comprehensive model has emerged-the social intuitionist model (Haidt, 2001), in which one of the key aspects of moral judgment relates to the human disposition to make quick affective evaluations of the actions of themselves and others (Haidt, 2001).

The work conducted on the development of prosocial behaviour has been largely influenced by Piaget and Kohlberg. To Piaget, morality is acquired through invariant stages as a function of sociocognitive development, by way of individual's reciprocal interactions with the environment, leading to increased perspective taking abilities and diminished egocentrism (Piaget, 1965). Kohlberg expanded this theory and suggested a six-level progression of moral development, through which the ability to ' role take' expands (Kohlberg et al., 1983). More recently, it has been suggested that the emergence of early morality depends on the intertwined development of self-awareness and the child's knowledge of "right" and "wrong", as well as the understanding of social behavioural standards and rules (Kochanska et al., 2002). The elaboration of a representation of the self in the second yearwhich helps the children to realize their role as causal agents (Kagan, 1984)-accompanies the child's understanding of intentionality (Kochanska et al., 1995). These developmental processes are the necessary underpinnings of the moral, higher-order, emotions such as guilt or shame, and the experience of other unpleasant affect in the context of wrongdoing (Lewis et al., 1989). Guilt and shame are labelled 'self-conscious' emotions because the individual's understanding and evaluation of the self are fundamental to these emotions (Eisenberg, 2000). They are believed to represent affective reactions that serve an adaptive function regarding moral conduct by providing reinforcement so as to prohibit socially disruptive acts (Nichols, 2002).

The understanding of moral transgressions and their affective consequences seems therefore influenced by two core aspects, namely intentionality and agency. Both aspects are a cornerstone in our various moral and legal formulations of codes of conduct. The 
individual's judgment of a transgression depends on whether the act was performed by him/herself or by somebody else (Sokol et al., 2004). Furthermore, the affective evaluation of a social violation is categorically different if the action was intentional or accidental, even if the physical consequences were identical (Baird and Astington, 2004). Indeed, when a transgression is intentional, only people who are able to pursue their own plans are perceived as intentional agents, and therefore seen to be responsible for their actions and to be deserving of whatever punishment our legal systems specify (Sokol et al., 2004).

Thus, it is reasonable to assume that the neural systems mediating the emotional evaluation of social norm's violation differ as a function of whether a transgression is intentional or accidental, and whether one is the agent of, or witness to, a social transgression. However, little is known on how moral judgements are implemented in the brain (Casebeer, 2003). Moreover, whereas a number of studies have identified that the medial prefrontal and orbitofrontal cortex, precuneus, superior temporal sulcus and the temporal lobes are modulated by agency and intentions in action/ movement recognition (e.g., Farrer et al., 2003; den Ouden et al., 2005), no previous brain imaging study has addressed these two core aspects in moral judgments.

Our working hypothesis is that the amygdala may be crucial for the evaluation of one's own social transgression (Dolan, 2002; Ochsner, 2004). Recent animal and human studies have highlighted distinct brain areas necessary for social judgments, including networks underlying emotional processing and reasoning, notably the ventro-medial prefrontal and orbitofrontal cortex, anterior cingulate cortex, superior temporal sulcus and the amygdala (Greene and Haidt, 2002; Adolphs, 2003). The few neuroimaging studies that have enquired into the neural organization of moral behaviour have identified a cortico-limbic network (Greene et al., 2001, 2004; Moll et al., 2002a,b; Takahashi et al., 2004). However, this did not include the amygdala, even though the amygdala has been implicated in complex emotional and social behaviours (Zald, 2003).

In non-human primate, amygdala lesioned monkeys were found socially uninhibited, i.e. they did not go through the normal period of evaluation of the social partner before engaging in social interactions (Amaral et al., 2003). In humans, the amygdala has been involved in emotional processing important for preserving one's own wellbeing, for instance in the perception of negatively and positively valenced stimuli and stimulus-affect association (Zald, 2003).

Given that moral transgressions expose the transgressor to criticism, rejection or other forms of punishment (Haidt, 2001), and that the amygdala activity appears closely tied to the context and level of aversiveness of the stimuli (Zald, 2003), the amygdala could be critically involved in the negative appraisal of a potential threat for the self in the context of one's own wrongdoing.

We used functional magnetic resonance imaging (fMRI) to investigate the neural networks that mediate the affective judgments associated with one's own intentional transgression of social norms. To do so, we re-analysed the data from Berthoz et al. (2002) study where both the intentionality of the violation (intentional vs. accidental) and the agency (self vs. other) were manipulated. In this experiment, subjects were scanned while making evaluations regarding the degree of inappropriateness of social behaviours described in stories in which they themselves, or someone else, transgressed social norms either intentionally or accidentally. This factorial design enabled us to look specifically for activations that related to who was intentionally violating social norms.

\section{Method}

\section{Participants}

Twelve right-handed males (mean age of $26.2 \pm 5.45$ years; range 19-37 years), free of past and present psychiatric or neurological disorder, participated in this study. Participants were required to have English as their first language. This study was approved by the Institute of Neurology Ethics Committee. Informed written consent was obtained from all subjects prior to scanning.

\section{Stimuli and task}

A two-way factorial experimental design was applied in which Intentionality of social norms transgression (Accidental, Intentional) and Agency (Self, Other) were factors. Thus, four types of verbal material were presented. These were short stories in which the story protagonist was either 'You' (Self) or someone else (Other), and in which a description was given either of an accidental violation of social norms, or a deliberate violation. Thus, the four types of stories were:

Self-Accidental (SA): the protagonist was the self, and the violation was accidental.

Other-Accidental (OA): the protagonist was another, and the violation was accidental.

Self-Intentional (SI): the protagonist was the self, and the violation was intentional.

Other-Intentional (OI): the protagonist was another, and the violation was intentional.

Importantly, the stories for self and others were identical, except for the agent performing the action. As a result, the stories were presented twice: once with a personal reference (i.e., the story protagonist is 'You'), and once with an impersonal reference (i.e., the story protagonist is someone else). The accidental and intentional stories were also matched in that the severity of the outcome was the same. There were 20 different stories for each condition. Examples are presented below.

Self Accidental violation (SA):

Beginning of the story: 'You are invited at a japanese dinner at a friend's house'.

Ending of the story: 'You have a bite of the first course, you choke and spit out the food while you are coughing'.

Other Accidental violation (OA):

Beginning of the story: 'Joanna is invited at a japanese dinner at her friend's house'.

Ending of the story: 'She has a bite of the first course, chokes and spits out the food while she is coughing'.

Self Intentional violation (SI):

Beginning of the story: 'You are invited at a japanese dinner at a friend's house'.

Ending of the story: 'You have a bite of the first course, but do not like it and spit the food back into your plate'.

Other Intentional violation (OI):

Beginning of the story: 'Joanna is invited at a japanese dinner at her friend's house'.

Ending of the story: 'She has a bite of the first course, but does not like it and spits the food back into her plate'. 
All stimuli were displayed on a monitor and presented to the participant via a $45^{\circ}$ angled mirror positioned above the head coil. This mirror was adjusted to be within the participant's field of vision without having to tilt the head. A test image was presented on the screen prior to scanning to ensure that the image was in focus and the participant could comfortably read the text. The beginning of each story was presented on the screen for $8 \mathrm{~s}$, and then replaced by the end of the story for $10 \mathrm{~s}$. The stories were separated by a 1 -s grey screen. The stimuli were presented in a pseudo-random order, so that the same story-with either self or other as protagonist-was not presented successively.

Participants were instructed to read the text silently, and to click the response-key when they finished reading the second part of the story. They were instructed to imagine what they/the story protagonist would feel (for the stories with a personal reference and an impersonal reference, respectively) in the situation described.

After the scanning session, half of the participants rated the stories in which the protagonist was 'You' (Self), and the other half rated the stories in which the protagonist was someone else (Other). For each story they had to rate (i) how embarrassing they thought the situation to be; (ii) how inappropriate they thought the behaviour to be; (iii) how funny they thought the story to be. No difference between the personal and impersonal ratings was found. Ratings of the inappropriateness of behaviour, regardless of agency, were significantly greater for the intentional violations than for the accidental violations. Conversely, mean embarrassment ratings, regardless of agency, were significantly greater for the accidental violations than for the intentional ones. Intentional and accidental violations were rated as similarly funny. Detailed description of the validation of the material and behavioural results has been described elsewhere (Berthoz et al., 2002).

\section{fMRI procedures}

Data were acquired on a $2 \mathrm{~T}$ Siemens VISION whole-body MRI system equipped with a head volume coil. T2*-weighted echoplanar image volumes were acquired, in an axial orientation, using the BOLD contrast. A total of 1020 images (510 images per run) were taken for each participant, each comprising a full brain volume of 40 contiguous axial slices ( $1.8 \mathrm{~mm}$ thickness). Volumes were acquired continuously with an effective repetition time (TR) of $3.04 \mathrm{sec}$. A T1-weighted anatomical MRI was also acquired for each subject.

Using statistical parametric mapping (SPM99) (Friston et al., 1994; Worsley and Friston, 1995), images were realigned to the first volume of each session to correct for inter-scan movement and spatially normalized to standard Talairach space using the MNI template (Evans et al., 1994). Finally, the images were spatially smoothed using an $8 \mathrm{~mm}$ (FWHM) Gaussian kernel. The evoked responses for the different experimental conditions were modelled using a boxcar of 10-s duration convolved with a synthetic hemodynamic response function (HRF). Key presses were modelled using a delta function convolved with the synthetic HRF. The movement parameters obtained from the realignment procedure were also included in the model as confounds to minimize the chances of detecting false activations due to movement artefacts.

We re-analysed the data from Berthoz et al. (2002) by performing a random effects analysis using Statistical Parametric Mapping SPM2 (Wellcome Department of Imaging Neuroscience,
London, UK). Images of parameter estimates for each condition of interest were created for each subject (first-level analysis), smoothed using a $6 \mathrm{~mm}$ (FWHM) Gaussian kernel, and flipped to be compatible with SPM2. They were then entered into a secondlevel analysis using ANOVAs with the four HRFs comprising a factor. Statistical Parametric Maps (SPMs) of the T-statistic were constructed using a generalised Greenhouse-Geiser correction. The statistical parametric maps were thresholded at $P<0.001$ (uncorrected for multiple comparisons), except for the amygdala, where, based on our a priori hypothesis, we used $P<0.005$ (uncorrected). An extend threshold of 10 voxels was also applied. These maps were overlaid on the MNI template and on the normalised structural images of each subject, and labelled using the atlas of Duvernoy (1999).

\section{Results}

We first analyzed the main effects of Intentionality [(SI + OI) versus $(\mathrm{SA}+\mathrm{OA})]$. When Intentional transgressions were compared with the Accidental ones (Intentional > Accidental), significant differential activation was seen in left dorsolateral, superior frontal cortex, anterior cingulate gyrus, left inferior parietal cortex, left superior occipital gyrus, left amygdala, right cerebellum and bilaterally in the precuneus (exact coordinates are given in Table 1). In the inverse contrast (Accidental $>$ Intentional), the only significant focus of differential activity was seen in the right temporal pole (see Table 1). These results are very similar to those obtained in our previous analysis (Berthoz et al., 2002) in which we used stories depicting a normal behaviour as the baseline condition and collapsed personal and impersonal stories. In addition, we showed amygdala activation when comparing intentional transgressions to accidental ones. The detection of amygdala activation in the present analysis may be explained by the direct comparison between conditions of interest as well as the use of SPM2.

We then calculated the main effects of Agency [(SI $+\mathrm{SA})$ versus $(\mathrm{OI}+\mathrm{OA})]$. When transgressions performed by the Self were compared with those performed by Another (Self $>$ Other), significant differential activation was seen in the left precuneus $(x, y, z=-6,-54,50, Z=3.21)$ and the right cerebellum $(x, y, z=$

Table 1

Brain activity related to main effects of Intentionality (Intentional versus Accidental) of social norm's violation

\begin{tabular}{lcrrr}
\hline Region & Z-score & \multicolumn{3}{l}{ Coordinates } \\
\cline { 3 - 5 } & & $x$ & $y$ & $z$ \\
\hline $\begin{array}{l}\text { Intentional minus Accidental violation } \\
\text { Left dorsolateral prefrontal/superior }\end{array}$ & 4.16 & -28 & 36 & 42 \\
$\quad$ frontal cortex & & & & \\
Left anterior cingulate cortex & 4.32 & -12 & 56 & 8 \\
Left inferior parietal lobe & 3.77 & -48 & -32 & 52 \\
Left occipital superior gyrus & 3.92 & -40 & -74 & 32 \\
Left amygdala & 3.72 & -16 & -6 & -22 \\
Right precuneus & 3.98 & 12 & -52 & 50 \\
Left precuneus & 3.36 & -6 & -60 & 48 \\
Right cerebellum & 3.33 & 34 & -56 & -50 \\
& & & & \\
Accidental minus Intentional violation & & & & \\
Right inferior temporal gyrus & 4.11 & 54 & -16 & -16 \\
\hline
\end{tabular}


a.

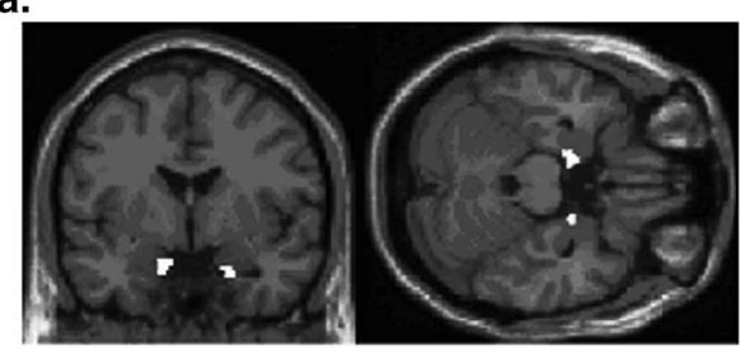

b.

Contrast estimates and $90 \%$ C.I. effects of interest at [22-2-26]

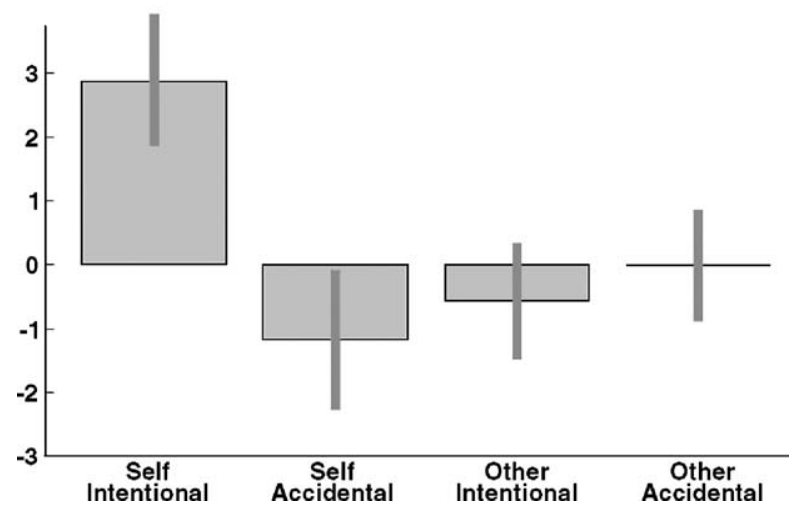

Fig. 1. Amygdala activation to one's own moral violation. (a) Statistical parametric map, overlayed onto the canonical MNI brain, showing the voxels within the amygdala where a significant interaction between Intentionality in violating social norms and Agency was observed $(P<$ 0.005); (b) Parameter estimates of the local maxima in the right amygdala $(x, y, z=22,-2,-26)$ show greater response when the social violation was performed by the self and was intentional, as compared to the other conditions. C.I.: Confidence Interval.

$32,-76,-30, Z=3.47$ ). In the opposite comparison (Other > Self), no significant difference of activation was detected.

In order to identify brain areas specifically activated when evaluating self involvement in intentional violation of social norms, the following contrast [(SI-OI)-(SA-OA)] was calculated. This interaction revealed significant bilateral amygdala activation (Right amygdala, $x, y, z=24,-4,-26, Z=2.78, P=0.003$; Left amygdala, $x, y, z=-10,-2,-24, Z=2.90, P=0.002$; see Fig. 1a). A post hoc exploration of the parameter estimates showed that this effect was driven by a greater response to Self Intentional violation as compared to all other conditions (see Fig. 1b). The only region that showed greater activation, at a threshold set to $P<0.001$, was the right dorsolateral prefrontal cortex ( $x, y, z=28,42,26, Z=3.49)$.

To identify brain areas specifically activated when evaluating self involvement in accidental violation of social norms, the following contrast $[(\mathrm{SA}-\mathrm{OA})-(\mathrm{SI}-\mathrm{OI})]$ was calculated. This interaction revealed significant increased activation in the left parieto-occipital fissure $(x, y, z=-14,-70,30, Z=3.43)$ and the left cerebellum $(x, y, z=-6,-46,-46, Z=3.51)$.

\section{Discussion}

The aim of the study was to specifically investigate whether amygdala activity is modulated by intentionality and agency in the perception of the transgression of social norms. The neural systems supporting the processing of intentional and accidental transgressions of social norms (relative to normal social behaviours), regardless of agency, have been discussed elsewhere (Berthoz et al., 2002; see also Greene and Haidt, 2002; and Casebeer, 2003 for a review on the brain areas involved in moral cognition). Here we focused on the interaction between intentionality and agency in the factorial design.

Our critical finding was enhanced activity in the amygdala when participants were presented with stories that narrated their own intentional violation of social norms. Our factorial design, which manipulated both the intentionality of the violation (intentional vs. accidental) and the agency (self vs. other), made possible to identify brain areas specifically activated when evaluating self involvement in intentional violation of social norms. This analysis revealed greater amygdala activation in response to Self Intentional violation as compared to all the other experimental conditions.

The amygdala is a crucial part of the neural circuitry by which stimuli trigger emotional responses that reflect an appraisal of value (Adolphs, 1999; Dolan, 2002). This is true whether the stimuli are social (Aggleton and Passingham, 1981; Meunier et al., 1999) or not (LeDoux, 2000), and whether the stimuli are visual, auditory or verbal (Zald, 2003). The emotional responses could serve to modulate and bias behaviour, depending on the appraised valence of the stimuli (Dolan, 2002). The amygdala is also known to play a role in perceiving other people's emotional states (Adolphs, 2003; Nishijo et al., 2003; Zald, 2003). Given the amygdala's hypothesized role in emotional evaluation, it seems reasonable to suggest that it is the subjective emotional response that produces the amygdala activation in the present study. Indeed, the participants had to imagine what they/the story protagonist would feel in the situation described.

It has been documented that the intensity of affective responses directly relates to the magnitude of the amygdala activity (Zald, 2003). However, the question arises as to why the emotional response was enhanced when subjects evaluated their own intentional transgression of social norms as compared to the other experimental conditions. One possible explanation relies on the putative functions of the amygdala in associations based on reward and punishment (Rolls, 2000) related to the anticipation of an aversive event (Zald, 2003). In the present study, the affective evaluation of one's own intentional transgression (i.e., I hurt you purposely) could elicit the anticipation of possible punishment as a consequence of one's own immoral behaviour. In contrast, no punishment is expected if the violation is unintended, as the transgressor usually makes clear that they acknowledge that his/her behaviour has affected the wellbeing of another so as to restore the social relationship (Keltner, 1995). Similarly, no personal punishment is expected when the observer witnesses others violating social norms.

However, additional measurements of the emotional response elicited by the different experimental conditions, such as selfreported feelings and galvanic skin response, are required to adduce some support for this interpretation. One limitation of the present study is that, after the scanning session, half of the participants $(n=6)$ rated the personal stories (SA and SI), whereas the other half rated the impersonal stories (OA and OI). This procedure prevented us from analysing whether differences in amygdala activation were correlated with the strength of embarrassment and inappropriateness associated with the different conditions. 
The fact the amygdala was activated for intentional violation by the self alone, is consistent with the view that this structure is involved in emotional processing important for personal welfare, as in the perception of emotionally salient stimuli and stimulus-affect contingencies (Adolphs, 2003; Dolan, 2002). Thus, the present results further emphasize the role of the amygdala in weighing the consequence of one's own intentional action for the sake of one's own wellbeing. The previous neuroimaging studies on the neural correlates of morality did not address the influence of intentionality and agency, which are two core aspects in moral judgment (e.g., Greene et al., 2001; Moll et al., 2002a,b). For example, in Moll et al. (2002b) study, the subjects were instructed to read emotional unpleasant moral and non moral statements and to covertly judge them as being either right or wrong. However, these instructions did not require reference to the subject's own behaviour. This may explain why the amygdala was not activated in the moral judgement condition, even though the stimuli were rated as emotionally evocative. More recently, these authors (Moll et al., 2005) found amygdala activation when comparing statements evocative of pure disgust (e.g., 'One night you were walking on the street. You saw a cat eating its own excrement') to indignation (e.g., 'You went with a friend to a restaurant. When you passed the kitchen, you saw rats in the pans'). Although the statements had a personal perspective ('You'), the participants were passive observers rather than being the agent of intentional social transgressions.

Further studies are needed to decide whether the amygdala activation found in the present study in Self Intentional condition reflects the anticipation of punishment.

A second possible explanation relies on the possible induction of negative self-conscious moral emotions, i.e. guilt and/or shame. These moral emotions are closely linked to the issue of intentionality and agency. Both emotions involve a sense of responsibility, the feeling that one has violated a moral standard, and would help to undercut immoral behaviour (Eisenberg, 2000). In developmental and social psychology, guilt often refers to regret over wrongdoing (Eisenberg, 2000). Guilt is a higher-order, moral emotion considered to arise from the self's negative evaluation of one's own behaviours or transgressions. It has been defined as an uncomfortable feeling resulting from the commission or contemplation of a specific act that is contrary to one's internalized standards of conduct; it requires reparative action for the harm done to another so as to alleviate the uncomfortable feeling (distress) (Robertson, 1994). The guilty actor accepts the responsibility for a behaviour that violates internalized standards or causes another's distress and desires to make amends or punish the self (Eisenberg, 2000). Shame also arises from concerns about the effects of one's behaviour on others, and guilt and shame often co-occur (Eisenberg, 2000). However, whereas guilt would involve the desire to undo aspects of behaviour, shame would be associated with the desire to undo aspects of the self (Niedenthal et al., 1994), which may explain that guilt is viewed as the more moral emotion of the two (Eisenberg, 2000).

In any case, as a result of morally wrong action, one is prone to analyse one's own behaviour and blame oneself. In the present study, the evaluation of one's own transgression induces the inference that one is responsible for the fact that the injured party will experience negative affect, and this in turn will evoke feelings of guilt. These associations are not provoked by the other experimental conditions. Interestingly, it has been recently documented in young children that guilt relates positively to the development of self at 18 months and to moral self at 56 months (although other theorists see guilt as developing much later), and that proneness to guilt serves to inhibit children's tendency to violate rules (Kochanska et al., 2002). Whether the amygdala is important for the development of prosocial behaviour and moral concerns still has to be determined. Further studies will be needed to refine the understanding of the role of the amygdala in various moral emotions as regard to agency such as guilt, shame, jealousy or even pride.

Finally, the present study also provided evidence that discrete prefrontal cortical regions may be differentially involved in various aspects of social reasoning. The orbitofrontal, the medial and ventromedial prefrontal cortex have been consistently involved in moral decision-making, such as in ethical decision-making (Heekeren et al., 2003) or in the appraisal of moral violations (Berthoz et al., 2002; Greene et al., 2001,2004; Heekeren et al., 2005; Moll et al., 2002a,b, 2005). The present result of enhanced activity in the dorsolateral prefrontal cortex in response to Self Intentional violation is consistent with the results of other studies that reported dorsolateral prefrontal cortex activations in response to Self intentional immoral behaviour, i.e. voluntary lying or feigning memory loss (Lee et al., 2002; Phan et al., 2005). Additional studies, specifically designed to address the differential roles of the dorsal medial, dorsal lateral and ventral medial prefrontal cortex should help us to better understand whether similar or different frontal sub-regions are being recruited in various self-referential and social-cognitive processing.

In conclusion, the results provide striking evidence of amygdala involvement in the affective response to one's own moral transgressions. Moreover, this study provides additional support for the amygdala's critical role in human social cognition. To date, most studies have highlighted the role of the amygdala in making inferences regarding the mental states and/or intentions of others, as for example in processing facial expressions, or making judgments about approachability and trustworthiness. The present finding of its involvement in self evaluation in relation to social norms suggests the amygdala may also be critical for learning socially appropriate behaviour, given that social norms vary across cultures and are learned.

\section{Acknowledgments}

This work was supported by a program grant to J.G, R.E.P and R.J.D. from the Wellcome Trust and S.B. was funded by the Fyssen foundation.

\section{References}

Adolphs, R., 1999. Social cognition and the human brain. TICS 3, $469-479$.

Adolphs, R., 2003. Is the human amygdala specialized for processing social information? Ann. N. Y. Acad. Sci. 985, 326-340.

Aggleton, J.P., Passingham, R.E., 1981. Syndrome produced by lesions of the amygdala in monkeys Macaca mulatta. J. Comp. Physiol. Psychol. 95, 961-977.

Amaral, D.G., Bauman, M.D., Capitanio, J.P., Lavenex, P., Mason, W.A., Mauldin-Jourdain, M.L., Mendoza, S.P., 2003. The amygdala: is it an essential component of the neural network for social cognition? Neuropsychologia 41, 517-522.

Baird, J.A., Astington, J.W., 2004. The role of mental state understanding in the development of moral cognition and moral action. New Dir. Child Adolesc. Dev. 103, 37-49. 
Berthoz, S., Armony, J.L., Blair, R.J.R., Dolan, R.J., 2002. An fMRI study of intentional and unintentional embarrassing violations of social norms. Brain 125, 1678-1696.

Casebeer, W.D., 2003. Moral cognition and its neural constituents. Nat. Rev., Neurosci. 4, 841-846.

Den Ouden, H.E., Frith, U., Frith, C.D., Blakemore, S.J., 2005. Thinking about intentions. NeuroImage 28, 787-796.

Dolan, R.J., 2002. Emotion, cognition and behavior. Science 298, $1191-1194$.

Eisenberg, N., 2000. Emotion, regulation, and moral development. Annu. Rev. Psychol. 51, 665-697.

Duvernoy, H.M., 1999. The Human Brain. Surface, Blood Supply and Three-dimensional Sectional Anatomy. Springer Verlag, New York.

Evans, A.C., Kamber, M., Collins, D.L., MacDonald, D., 1994. An MRIbased probabilistic atlas of neuroanatomy. In: Shorvon, S., Fish, D., Andermann, F., Bydder, G.M., Stephan, H. (Eds.), Magnetic Resonance Scanning and Epilepsy. Plenum Press, New York, pp. 263-274.

Farrer, C., Franck, N., Georgieff, N., Frith, C.D., Decety, J., Jeannerod, M., 2003. Modulating the experience of agency: a positron emission tomography study. NeuroImage 18, 324-333.

Friston, K.J., Worsley, K.J., Frackowiak, R.S.J., Mazziotta, J.C., Evans, A.C., 1994. Assessing the significance of focal activations using their spatial extent. Hum. Brain Mapp. 1, 210-220.

Greene, J.D., 2003. From neural 'is' to moral 'ought': what are the moral implications of neuroscientific moral psychology. Nat. Rev., Neurosci. 4, $847-850$.

Greene, J.D., Haidt, J., 2002. How (and where) does moral judgment work? TICS 6, 517-523.

Greene, J.D., Sommerville, R.B., Nystrom, L.E., Darley, J.M., Cohen, J.D., 2001. An fMRI investigation of emotional engagement in moral judgment. Science 293, 2105-2108.

Greene, J.D., Nystrom, L.E., Engell, A.D., Darley, J.M., Cohen, J.D., 2004. The neural bases of cognitive conflict and control in moral judgment. Neuron 14, 389-400.

Hogan, R., 1973. Moral conduct and moral character: a psychological perspective. Psychol. Bull. 79, 217-232.

Haidt, J., 2001. The emotional dog and its rational tail: a societal intuitionist approach to moral judgment. Psychol. Rev. 108, 814-834.

Hawley, P.H., 2003. Strategies of control, aggression, and morality in preschoolers: an evolutionary perspective. J. Exp. Child. Psychol. 85, $213-235$

Heekeren, H.R., Wartenburger, I., Schmidt, H., Schwintowski, H.P., Villringer, A., 2003. An fMRI study of simple ethical decision-making. NeuroReport 14, 1215-1219.

Heekeren, H.R., Wartenburger, I., Schmidt, H., Prehn, K., Schwintowski, H.P., Villringer, A., 2005. Influence of bodily harm on neural correlates of semantic and moral decision-making. NeuroImage 24, $887-897$.

Kagan, J., 1984. The Nature of the Child. Basic Books, New York.

Keltner, D., 1995. Signs of appeasement: evidence for the distinct displays of embarrassment, amusement, and shame. J. Pers. Soc. Psychol. 68, $441-454$

Kochanska, G., Aksan, N., Koenig, A.L., 1995. A longitudinal study of the roots of preschoolers' conscience: committed compliance and emerging internalization. Child Dev. 66, 1752-1759.

Kochanska, G., Gross, J.N., Lin, M.-H., Nichols, K.E., 2002. Guilt in young children: development, determinants, and relations with a broader system of standards. Child Dev. 73, 461-482.

Kohlberg, L., Levine, C., Hewer, A., 1983. Moral Stages: a Current Formulation and a Response to Critics. Karger, Basel, Switzerland.

LeDoux, J.E., 2000. Emotion circuits in the brain. Annu. Rev. Neurosci. 23, $155-184$.

Lee, T.M., Liu, H.L., Tan, H.L., Chan, C.C., Mahankali, S., Feng, C.M., Hou, J., Fox, P.T., Gao, J.H., 2002. Lie detection by functional magnetic resonance imaging. Hum. Brain Mapp. 15, 157-164.

Lewis, M., Sullivan, M.W., Stanger, C., Weiss, M., 1989. Self-development and self-emotions. Child Dev. 60, 146-156.

Meunier, M., Bachevalier, J., Murray, E.A., Malkova, L., Mishkin, M., 1999. Effects of aspiration versus neurotoxic lesions of the amygdala on emotional responses in monkeys. Eur. J. Neurosci. 11, 4403-4418.

Moll, J., de Oliveira-Souza, R., Eslinger, P.J., Bramati, I.E., MouraoMiranda, J., Andreiuolo, P.A., Pessoa, L., 2002a. The neural correlates of moral sensitivity: a functional magnetic resonance imaging investigation of basic and moral emotions. J. Neurosci. 22, 2730-2736.

Moll, J., de Oliveira-Souza, R., Eslinger, P.J., Grafman, J., 2002b. Functional networks in emotional moral and nonmoral social judgments. NeuroImage 16, 696-703.

Moll, J., de Oliveira-Souza, R., Moll, F.T., Ignacio, F.A., Bramati, I.E., Caparelli-Daquer, E.M., Eslinger, P., 2005. The moral affiliation of disgust: a functional MRI study. Cogn. Behav. Neurol. 18, 68-78.

Nichols, S., 2002. Norms with feeling: towards a psychological account of moral judgment. Cognition 84, 221-236.

Niedenthal, P.M., Tangney, J.P., Gavanski, I., 1994. "If only I weren't" versus "If only I hadn't": distinguishing shame and guilt in counterfactual thinking. J. Pers. Soc. Psychol. 67, 584-595.

Nishijo, H., Hori, E., Tazumi, T., Eifuku, S., Umeno, K., Tabuchi, E., Ono, T., 2003. Role of the monkey amygdala in social cognition. In: Ono, T., Matsumoto, G., Llinas, R.R., Berthoz, A., Norgren, R., Nishijo, H., Tamura, R. (Eds.), Cognition and Emotion in the Brain. Elsevier, Amsterdam, pp. 295-310.

Ochsner, K.N., 2004. Current directions in social cognitive neuroscience. Curr. Opin. Neurobiol. 14, 254-258.

Phan, K.L., Magalhaes, A., Ziemlewicz, T.J., Fitzgerald, D.A., Green, C., Smith, W., 2005. Neural correlates of telling lies: a functional magnetic resonance imaging study at 4 Tesla. Acad. Radiol. 12, 164-172.

Piaget, J., 1965. The Moral Judgment of the Child. Routledge and Kegan Paul, London.

Robertson, W.J., 1994. The concept of guilt. J. Psychosoc. Nurs. Ment. Health Serv. 32, 15-18.

Rolls, E.T., 2000. The orbitofrontal cortex and reward. Cereb. Cortex 10, 284-294.

Sokol, B.W., Chandler, M.J., Jones, C., 2004. From mechanical to autonomous agency: the relationship between children's moral judgments and their developing theories of mind. New Dir. Child Adolesc. Dev. 103, 19-36.

Takahashi, H., Yahata, N., Koeda, M., Matsuda, T., Asai, K., Okubo, Y., 2004. Brain activation associated with evaluative processes of guilt and embarrassment: an fMRI study. NeuroImage 23, 967-974.

Worsley, K.J., Friston, K.J., 1995. Analysis of fMRI time-series revisitedagain. NeuroImage 2, 173-181.

Zald, D.H., 2003. The human amygdala and the emotional evaluation of sensory stimuli. Brain Res. Rev. 41, 88-123. 